\title{
MELCHOR ALMAGRO SAN MARTÍN Y SUS COLABORACIONES EN REVISTAS LITERARIAS DE SU PRIMERA ETAPA $(1896-1914)^{1}$
}

\author{
AMELINA CORREA RAMÓN \\ amelina@ugr.es \\ Universidad de Granada
}

\section{Resumen}

El presente artículo constituye un repaso de las colaboraciones en revistas literarias de la primera etapa (1896-1914) del escritor Melchor Almagro San Martín (1881-1947), quien destacó en el género de la pequeña historia y mantuvo durante toda su vida una muy activa y fecunda relación con la prensa escrita, en sus más diversas variantes.

Palabras clave: Colaboraciones revistas literarias escritor Melchor Almagro San Martín 1896-1914

\begin{abstract}
This article is an overview of the Spanish writer Melchor Almagro San Martín (18811947)'s first contributions to literary magazines (1896-1914). Melchor Almagro excelled in the genre of «short history» and maintained a very active and fruitful relationship with the press throughout his life.
\end{abstract}

Keywords: Contributions literary magazines writer Melchor Almagro San Martín 1896-1914

1. En el presente trabajo se ha prestado atención a las colaboraciones de Melchor Almagro San Martín en revistas literarias correspondientes únicamente al periodo acotado, dejando de lado sus abundantes colaboraciones con otro tipo de publicaciones periódicas (colaboraciones, en muchas ocasiones, de índole claramente literaria), así como las colaboraciones en revistas literarias que exceden la fecha delimitada, es decir, posteriores a 1914.

Anales, 26, 2014, pp. 147-165

DOI: 10.14198/ALEUA.2014.26.06 
El día 7 de noviembre de 2013 fue inaugurada en el Palacio de Carlos V y en la Fundación Rodríguez Acosta de Granada una exposición sobre el escultor Juan Cristóbal (1896-1961)², almeriense afincado en Granada, y autor -entre otras obras dignas de mención, como pudiera ser la «Sibila», del Círculo de Bellas Artes de Madrid- del monumento a Ángel Ganivet en los bosques de la Alhambra. Dicho monumento, promovido por el Centro Artístico de la capital, fue inaugurado junto a la conocida como «Fuente del Tomate» el día 3 de octubre de 1921, asistiendo al acto numerosas personalidades relacionadas con la cultura granadina, como Natalio Rivas, Nicolás María López, Antonio Gallego Burín, Luis Seco de Lucena, y, entre otros, el escritor Melchor Almagro San Martín (cf. Correa Ramón 2001), del que precisamente Juan Cristóbal tallaría un espléndido busto, que se ha podido contemplar en la mencionada exposición. Este busto, cuya notoriedad lo llevaría a quedar reflejado en los medios de prensa del momento ${ }^{3}$, acompañó al escritor hasta sus últimos días ${ }^{4}$, e incluso, en la autobiografía que comenzó a publicar por episodios en el periódico El Español, desde abril de 1946 -un año antes de su muerte-, bajo el título global de Teatro del mundo. Recuerdos de mi vida, la evoca con la emoción de los días ya perdidos.

De hecho, Almagro San Martín dará comienzo a la escritura de su texto marcado por sentimientos de profundo pesimismo. Los ojos del autor parecen fijarse en aquellos objetos que lo rodean en su despacho, y sobre todo, en los diversos retratos que varios notables artistas le han ido haciendo a lo largo de su vida, cuya imagen contrasta amargamente con la que de él mismo le ofrece, envejecido ya y muy enfermo ${ }^{5}$, su espejo, recuerdos «todos evocadores de un pasado feliz» (Almagro San Martín 2001, pág. 39):

Unas cuantas fotografías que me representan de niño, amarilleadas por el tiempo, y los retratos de mis padres, debidos a Madrazo, evocan mi niñez. El pastel que López Mezquita pintara a fines del siglo pasado [...] para una

2. Bajo el título de «Juan Cristóbal (1896-1961)», la exposición ha sido comisariada por el profesor de la Universidad de Granada, Dr. Eduardo Quesada Dorador.

3. De hecho, el 13 de mayo de 1922 apareció reproducido en la revista La Esfera (Madrid), con el siguiente pie de foto: «Una obra del escultor Juan Cristóbal. Admirable busto del ilustre escritor y diplomático D. Melchor Almagro y San Martín».

4. Ocupaba un lugar relevante en el salón de su casa, como se puede comprobar por la acuarela de José Garrigues Motos que muestra al espectador el artístico y suntuoso interior de la misma, y que fue reproducida en la revista Elegancias (Madrid), n. ${ }^{\circ}$ 4, año I, abril de 1923.

5. Se puede recordar la evidencia de que Melchor Almagro fallecería el 12 de abril de 1947, un año después de comenzar a publicar por episodios en el periódico El Español (Madrid) sus memorias, bajo el título de Teatro del mundo. Recuerdos de mi vida, que quedarían, de esta manera, abruptamente interrumpidas. 
portada de El Cuento Semanal, fija mi juventud, el busto enérgico donde me reproduce Valentín de Zubiaurre, cristaliza mi adultez, mientras el busto admirable de mi persona en bronce, esculpido por Juan Cristóbal, y el retrato de cuerpo entero en uniforme diplomático, que firma también López Mezquita, representan mi madurez (Almagro San Martín 2001, pág. 39).

Almagro añadirá en su evocación:

Recordándome con melancolía el presente, hay también en este cuarto mío algunas tallas policromadas, un viejo reloj dorado a fuego, de sonería, petacas y sortijas dieciochescas, marfiles rotos, antañona plata cincelada, una Santa María Magdalena, del Greco, y una Sagrada Familia, de Memling, restos de mis colecciones artísticas (Almagro San Martín 2001, pág. 39).

Y es que Melchor Almagro amó tanto la Belleza, con mayúscula, que desde joven se dedicaría a coleccionar hermosos libros y objetos de arte, e incluso a hacer en buena medida de su propia trayectoria vital una cierta representación artística. De hecho, su morada llegará a ser bien conocida en el Madrid de los primeros años del siglo Xx por este motivo. Así, como persona de gustos estéticos refinados, y de holgada posición económica, la casa de la calle de Jorge Juan, en el acomodado Barrio de Salamanca, en la que habitará Almagro San Martín durante varias décadas, se convertirá en un ejemplo prototípico de residencia señorial, acondicionada con muebles antiguos y otros modernos de noble factura, así como con numerosos objetos de arte y multitud de libros, y como tal quedará reflejada en informaciones gráficas de la época.

En este sentido, las abundantes noticias que aparecen en la prensa periódica en torno a la activísima vida social que llevaba Melchor Almagro San Martín en las décadas previas a la Guerra Civil, dan cuenta de las frecuentes reuniones organizadas en su casa, incluyendo conciertos, recitales, tertulias, etcétera. En muchas de ellas, se llama la atención acerca del carácter exquisito, tanto de la vivienda como de su anfitrión. Es el caso, por ejemplo, de la extensa reseña firmada por el cronista de la vida social conocido como LeonBoyd, seudónimo de Enrique Casal, con el título «De sociedad. En casa de D. Melchor Almagro San Martín. En honor de Benavente», y publicada en marzo de 1922 en el periódico La Correspondencia de España, donde se puede leer: «Muy artística fue la [reunión] del domingo, no sólo por la casa, amueblada con refinado gusto y llena de obras de arte, en que descuellan esculturas de Alonso Cano, Diego de Siloé, Gregorio Hernández y Mora, sino por la concurrencia exclusivamente de grandes artistas y escritores» (Leon-Boyd 1922, pág. 5).

Entre los numerosos asistentes que menciona Casal, se refleja la presencia de nombres conocidos del mundo intelectual, artístico y literario. Así, se puede destacar la asistencia a este evento de la actriz Lola Membrives, Ramiro de 
Maeztu, los escultores Mariano Benlliure y el propio Juan Cristóbal, el ya citado pintor José María López Mezquita, escritores como los hermanos Álvarez Quintero, Antonio de Hoyos y Vinent, Joaquín Belda, Tomás Borrás, Cristóbal de Castro, su primo Melchor Fernández Almagro, Wenceslao Fernández Flórez, Carlos Fernández Shaw, Andrés González Blanco, Alberto Insúa, etcétera.

Leon-Boyd pone claramente de manifiesto el carácter intensamente esteticista y amante de los detalles del anfitrión, al señalar:

El té, servido en el comedor, tapizado con damascos rojos del siglo XVII, sobre los cuales se destaca una hermosa colección de plata repujada, fue espléndido e hizo honor al cocinero de la casa.

Todos los salones aparecieron florecidos con una primavera temprana, en que descollaban, blancas y perfumadas, las flores de almendro» (Leon-Boyd 1922, pág. 5).

Años después, con posterioridad a la contienda civil, Melchor Almagro se vería obligado a instalarse en una más reducida y un tanto modesta vivienda de la también calle madrileña de Claudio Coello. Él mismo lo relatará en un artículo publicado el Día del Libro de 1944: «Fuerza me fue abandonar el domicilio donde habían transcurrido cuarenta años de mi vida e instalarme en un pequeñísimo apartamento, único desalquilado que a la sazón pude encontrar» (Almagro San Martín 1944, pág. 1). Habiendo perdido, como azarosa consecuencia de la guerra, buena parte de sus colecciones artísticas y de su biblioteca, lograría salvar, no obstante, lo suficiente como para continuar causando impresión en las visitas de índole literaria o intelectual que aún recibe en su morada. De hecho, cuando a ella acuda la joven escritora asturiana Ángeles Villarta, colaboradora del semanario Domingo -en el que también publicará con frecuencia Almagro, alcanzando hasta un total de ciento cincuenta artículos, entre finales de 1939 y finales de 1946-, con el fin de hacerle una entrevista, impactada por lo que ve describirá los innumerables objetos de arte o de coleccionismo que decoran abigarradamente los espacios por los que va transitando en su paseo por la casa:

A la izquierda del pasillo un gran espejo; a la derecha, una cómoda antigua. Sobre la cómoda, un cuadro de Murillo. Un enorme farol de los que solían acompañar en palacio al Viático. Más pinturas y esculturas -encantadora la de una santa Bárbara, mutilada, del siglo XIV-. Sobre la puerta, un marco de estilo barroco. [...]

Luego [...] Mesas, veladorcitos, un sofá isabelino, bibliotecas, un mueble de tipo oriental, unos lindos angelotes, más cuadros, todos de mérito; más espejos, más esculturas, una greca de rosas de oro (Villarta 1944, pág. 3).

La entrevista de Ángeles Villarta se produce con motivo de la exitosa publicación por parte de Melchor Almagro de su libro Biografía del 1900, el cual 
alcanzará dos ediciones en corto plazo y que representa un fecundo cruce de géneros literarios, conjugando autobiografía, diario y el subgénero de origen francés, en el que el escritor granadino sería considerado en su época un maestro, como era el de la petite histoire. En la España actual se ha perdido el matiz verdadero del significado de esta expresión, que no es el de «historia sin importancia» o «historia de segunda», sino historia de la vida cotidiana. Según aclarará en un artículo el propio autor, «La pequeña historia es clave explicatoria de la grande, a cuya luz se discrimina a la persona del personaje, al hombre de carne, del figurón transmutado de aquél» (Almagro San Martín 1946, pág. 3).

Melchor Almagro escribe su Biografía del 1900 por encargo de la Revista de Occidente, como parte de una ambiciosa colección titulada «Vidas de años», que tenía la intención de dedicar un volumen a determinados ciclos anuales, y, en especial, a algunos momentos que por uno u otro motivo habían resultado especialmente significativos en el devenir de la España contemporánea. Finalmente, muy pocos de estos proyectados volúmenes alcanzarían a ver la luz, pero sí lo haría el encomendado a Almagro, quien utilizó para ello los diarios que acostumbraba a llevar ya desde muy joven.

De hecho, Biografía del 1900, que se caracteriza por su prosa luminosa y vívida, alcanzó un éxito inmediato que hizo que se agotara la primera edición en poco más de un mes, y que se preparara una nueva, que presentó ciertas modificaciones. En esta obra, que Emilio Carrere definirá como «crónica del 1900 [que] tiene un encanto frívolo e inteligente» (Carrere 1943, pág. 3), Melchor Almagro relata con extrema amenidad cómo era la vida española del crucial periodo de entresiglos, inmersa en plena crisis finisecular, con sus debates internos, sus conflictos políticos, sociales, estéticos, literarios, la pobreza de su vida universitaria, pero también sumergida de lleno en diversiones y festejos de todo tipo: carnavales, cotillones, teatros, corridas de toros...; una animada vida social bajo la cual latía, ya inadvertidamente, un germen que acabaría llevando a la destrucción.

Perteneciente a una acomodada y culta familia granadina, su padre había sido el prestigioso abogado y diputado a Cortes Melchor Almagro Díaz, intelectual cercano a las posiciones políticas de Emilio Castelar, que falleció prematuramente en 1893 (cf. Viñes Millet 1999), cuando Melchor tenía tan sólo once años, y en cuya mansión granadina disfrutó su hijo de una intensísima vida social y cultural desde su primera infancia, acostumbrado al trato frecuente con escritores, artistas, intelectuales y otras personalidades del momento. Ya en esta temprana etapa se pondrá de manifiesto la doble vocación que singularizaría a Melchor Almagro San Martín durante toda su vida, que se 
caracterizará por su afición hacia la literatura de carácter autobiográfico, por un lado, y hacia las colaboraciones en la prensa periódica, tan importante en la época, por otro.

En efecto, la precocidad de Melchor Almagro, que destacará con enorme brillantez en todas las etapas de sus estudios, se pondrá de relieve igualmente en otras facetas, también relacionadas con la cultura y, de manera especial, con las letras. Así, por ejemplo, se puede destacar su ya mencionada costumbre de llevar un diario, que lo acompañará durante buena parte de su vida, y que iniciaría a edad verdaderamente temprana. A pesar de los más diversos azares del destino, la suerte permitió que se salvara un pequeño cuadernito, donde con letra escolar de un niño que aún no ha cumplido los once años edad, puede leerse: «Memorias de Melchor Almagro Sanmartín».

Se trata, en realidad, de un diario correspondiente al año 1893 -el año del fallecimiento de su padre-, en el que va apuntando desde el primer día del mes de enero los sucesos cotidianos propios de la niñez. A veces con caligrafía muy esmerada e incluyendo dibujos, y otras escribiendo apresurado y sintiéndose obligado a rellenar el espacio correspondiente a cada día, Melchor Almagro completará en esta ocasión tan sólo los tres primeros meses del año. Resulta curioso constatar que, siendo tan sólo un niño, demuestra ya una precoz afición por el teatro -faceta que se revela muy evidente con la lectura de su obra posterior-, hasta el punto de encontrarse lo que podríamos considerar un atisbo de crítica teatral de las obras presenciadas. Así, en la entrada correspondiente al «Sábado 10 de Marzo 1893», anota: «Por el día he ido a el colegio y por la noche a el teatro a ver Mariana mañana expondré mi opinión $[s i c] »^{6}$. En el siguiente apunte, anota: «Respecto a la función de anoche la obra buena los actores malos» ${ }^{\top}$.

Tres años más tarde, y aun antes de cumplir los catorce de edad, se pone claramente de manifiesto su precoz y viva vocación literaria volcada en la segunda de las facetas mencionadas, puesto que se presentará desde un primer momento vinculada a la prensa periódica de carácter literario. De este modo, Almagro, poniendo además de relieve su carácter emprendedor, funda adolescente junto con un grupo de intrépidos colaboradores y condiscípulos la revista semanal Nuestros días festivos, que pasa a titularse Semanario infantil

6. En las transcripciones se respeta la ortografía y puntuación tal cual aparece en el manuscrito.

7. Transcrito de la fotocopia del mencionado documento original, amablemente facilitada por D. Juan Ramón Pastor Almagro, sobrino nieto del escritor (descendiente directo de su hermano José Almagro San Martín, 1883-1943). 
a partir del segundo número, editándose entre los meses de marzo y agosto de 1896.

En relación con la temprana fundación de esta revista, se puede recordar la similitud que muestra con el caso del escritor francés Victor Hugo, quien, de hecho, fundaría junto con sus hermanos Abel y Eugène en 1819 -esto es, a sus diecisiete años de edad- una revista bautizada como Le Conservateur Littéraire, donde dará a conocer poemas y artículos. Al parecer, el espíritu del siglo inspiraba adolescencias entusiastas y emprendedoras, puesto que, entre otros ejemplos, la misma iniciativa iba a tener aún un más precoz Alejandro Sawa, quien poco antes de cumplir quince años ya había puesto en marcha, en colaboración con su hermano Manuel y otros jóvenes amigos, el efímero periódico titulado elocuentemente Ecos de la juventud (1877), al que seguirían poco después El Siglo XIX (1877) y La Joven Málaga (1878) (cf. Correa Ramón 2009, págs. 46-50).

La similitud que presenta la iniciativa de Almagro y sus amigos en relación con la que casi dos décadas antes llevara a cabo Alejandro Sawa, pasa de igual modo por el establecimiento de la redacción en el propio domicilio de los precoces escritores. Así, las referidas publicaciones malagueñas ofrecerán como dirección de referencia el número 22 de la céntrica Plaza de la Merced (un edificio de construcción decimonónica idéntico al que verá el nacimiento en 1881 de Pablo Ruiz Picasso, en el número 15 del mismo lateral, donde hoy en día se sitúa la Fundación de su nombre), lugar en el que vivían los Sawa Martínez, mientras que la granadina Semanario Infantil ${ }^{8}$ proporcionará el de Águila, 3, número que corresponde al palacete familiar de los Almagro San Martín:

Vivíamos desde que tuve uso de razón, hasta que de la bella capital andaluza transferimos nuestros penates a la villa y corte, en una casa solariega, que había pertenecido antes a la noble familia histórica de los Henríquez, situada en el número 3 de la calle del Águila, con cancelas y patio de mármol blanco provisto de amplios cenadores, a quienes sostenían airosas columnas de igual piedra. Contra el muro central, un pilar, coronado por el blasón heráldico de los antiguos dueños de la morada, todo él en mármol de Sierra Elvira, que, como es sabido, posee un bello matiz azulado. De igual materia estaba hecha la fuente, en forma de artificiosa concha circular, con un surtidor en medio, que acompañaba con el rumor de su chorro saltarín a modo de canción de cuna, nuestras dulces siestas de estío, que solíamos pasar en la ciudad (Almagro San Martín 2001, pág. 55).

8. En cambio, en Nuestros días festivos no consta dirección alguna para la redacción. 
La revista Nuestros días festivos va a iniciar su andadura, con periodicidad semanal, el día 22 de marzo de 1896, ofreciendo a sus lectores un breve formato de tan sólo cuatro páginas y un contenido de marcado carácter artístico y literario. Conviene señalar que los diversos periódicos de Granada saludan la iniciativa, subrayando la extrema juventud de sus editores, «alumnos del Colegio de PP. Escolapios» («Semanario simpático» 1896, pág. 1), en el que, efectivamente, estudió el escritor. De este modo, el bisemanario La Opinión destacará que se trata de una «hermosa revista», así como despierta la admiración el estar impulsado por «jóvenes que ninguno cuenta más de doce años» («Bibliografía» 1896, pág. 3).

Una semana más tarde, el 29 de marzo, la revista, como ya se ha adelantado, cambiará su nombre por el de Semanario infantil, manteniéndose idénticos su enfoque, periodicidad y director (Eduardo García Carrera). Sin embargo, cambiará mínimamente su tamaño, pasando de $31 \times 22$ a 32×22 cm. (cf. Manjón-Cabeza 1995, vol. I, págs. 374 y 464). La publicación logrará mantenerse hasta el 11 de septiembre de ese año. En ella, dará a conocer Almagro un total de quince artículos -uno en Nuestros días festivos y catorce en Semanario infantil-, de diferentes temáticas, debiendo destacarse el titulado «A mi padre», que publica evocando la figura paterna, en un número del Semanario infantil dedicado monográficamente a la figura del desaparecido prócer granadino con motivo del tercer aniversario de su muerte, en el mes de junio. El entrañable amor filial junto con la admiración que Melchor sintió por su progenitor quedan puestos de relieve en una prosa dictada por la grandilocuencia retórica del adolescente:

Con lágrimas en los ojos cojo la pluma en el día de hoy 7 de Junio, aciago y desgraciado sobremanera para mí, pues en aquel infausto día mi padre murió; mi padre a quien yo adoraba; mi padre que al morir arrancó la alegría y la felicidad de nuestra antes risueña casa despedazándonos el corazón.

Desde entonces todo es negro y tétrico para mí, si alguna vez triunfó mi alegría se torna en pesares, al recordar que ya no existe aquel a quien yo ofrecía mis trabajos (Almagro San Martín 1896, pág. 2).

Menos de un año después de la finalización de Semanario infantil, tendrá lugar un importante hito en la trayectoria literaria y vital del jovencísimo Melchor Almagro, cuando en el verano de 1897 conozca a Ángel Ganivet, lúcido escritor y animador de la finisecular Cofradía del Avellano, que se encuentra de vacaciones en su ciudad natal, descansando de su trabajo como diplomático. En este grupo experimentará Ganivet su teoría del crecimiento espiritual de las ciudades "por medio -como explicará en 1896 en su libro Granada la bellade la vida bella, culta y noble de los seres que las habitan», tratando de alentar en sus contertulios la reactivación de sus voluntades dormidas (Ganivet 1996, 
pág. 62). Almagro se integrará enseguida con mirada fascinada en el grupo renovador, lo que recordará en reiteradas ocasiones a lo largo de su vida:

Junto a la fuente, tras larga y despaciosa caminata, se instalaba la Cofradía, y allí [...] se discurría sobre todos los grandes problemas del mundo, se leían artículos y poesías, se comentaban los libros. Cuando venía la noche, y de la vecina Abadía llegaban las campanadas del Angelus, comenzaba el lento regreso hacia Granada entre deleitosos comentarios (Almagro San Martín 1945, pág. 183).

Y, precisamente dedicado a uno de sus compañeros en dicha agrupación, aparecerá en la primavera de 1898 el texto titulado «Niñerías», firmado por Melchor Almagro San Martín, que acaba de cumplir en abril los dieciséis. Con carácter narrativo, el breve cuento se publica en la espléndida revista granadina La Alhambra, recién fundada el 15 de enero de ese mismo año y dirigida por el erudito Francisco de Paula Valladar, y lleva la siguiente dedicatoria: «Al castizo escritor y querido amigo Matías Méndez Vellido», autor de carácter costumbrista, que colaboraría con Ángel Ganivet en el proyecto común del renovador Libro de Granada (1899), y que sería considerado por éste nada menos que como el mejor novelista granadino después de Pedro Antonio de Alarcón. La intención de la dedicatoria podría adivinarse en el estilo que un muy juvenil Almagro pareciera querer, de alguna manera, emular:

Y es verdad que el mozo tenía razón para estar alelado y confuso con el cambio experimentado: desde su agreste pueblecillo a la barahúnda ensordecedora de la capital; de oír las cariñosas frases y sanos consejos de su vieja madre a escuchar las peladas órdenes del capitán [...]; de labrar la tierra, correr los campos sobre un rucio pollino y a veces cortar fresca yerba para los conejillos del corral, a limpiar porcelanazas vajillas, llevar mensajes, hacer encargos y servir la mesa de Cemines (Almagro San Martín 1898, pág. 153).

Fundada por el propio Francisco de Paula Valladar, tras un anterior intento frustrado que había durado poco más de un año, entre enero de 1884 y junio de 1885, la revista, de periodicidad quincenal, heredaba una cabecera de título reiterado en varias publicaciones periódicas a lo largo del siglo XIX, como pone de manifiesto la Guía de la prensa de Granada y provincia de Antonio Manjón-Cabeza (Manjón-Cabeza Sánchez 1995, vol. I, págs. 42-47). La Alhambra, subtitulada Revista quincenal de artes y letras, surge con la vocación de crear y mantener en Granada un ambiente artístico y literario, y con tal vocación y el tesón inquebrantable de su fundador y director se mantuvo durante veinticinco años, hasta la muerte de éste, que tendría lugar en febrero de 1924 (cf. Pardo López; Guervós Madrid 1957).

Desde sus comienzos trató además Valladar, con muy buen criterio, de romper con el aislamiento localista que solía caracterizar a las revistas editadas 
en provincias, mediante una activa red de intercambio con otras publicaciones, muy en especial, con aquellas -como Álbum Salón o El Eco de Sitges-que servían de reflejo de las actividades de grupos de intelectuales y artistas de Cataluña, con los que existió una temprana relación propiciada por los contactos de Ángel Ganivet con Santiago Rusiñol y su Cau Ferrat, además de con diversas revistas de ámbito nacional que contaban ya con una indudable solera, como Revista contemporánea (1875-1907). Por supuesto, también se prestó especial atención a otras iniciativas que surgían en esos años, como Vida nueva (1898-1900), cuyos contenidos se comentaban en los diversos números de La Alhambra, o publicaciones efímeras fundadas poco después, como Revista Nueva, dirigida por Luis Ruiz Contreras, o La vida literaria, ambas de 1899.

En este sentido, habría que añadir que se estableció una corresponsalía permanente, concretada en la sección «La Alhambra en Madrid», que cada quince días enviaba desde la capital el escritor Eduardo de Bustamante. Asimismo, se daba cuenta de la recepción en el domicilio editorial de numerosas revistas, tanto europeas como hispanoamericanas, y libros de toda índole y temática que eran comentados, siquiera mínimamente, con el meritorio objetivo de intentar ampliar el panorama intelectual de los lectores de la publicación granadina.

Paralelamente, las páginas de la revista estuvieron siempre abiertas a escritores de todas las tendencias y estilos, encontrando cabida tanto la literatura de creación como los estudios de tipo artístico o histórico y la crítica literaria, que a menudo llevaba a cabo el propio Valladar, quien realizaba, sin duda, una labor ímproba. En cuanto a la orientación ideológica y estética de la revista, La Alhambra se caracterizó siempre por un eclecticismo donde el más novedoso modernismo compartía espacio con los usos narrativos y poéticos decimonónicos.

Precisamente a la etapa plenamente modernista de Melchor Almagro San Martín pertenecerá ya su segunda -y última- colaboración en La Alhambra. Se trata de su texto titulado "De Andalucía la triste. Fragmento de una carta», que aparece en 1903, el año de publicación de su primer libro, el conjunto de relatos Sombras de vida, que ve la luz con un elogioso prólogo de Ramón del Valle-Inclán. Escritos en una prosa decadente y esteticista, y con un estilo en buena medida cercano al Valle-Inclán de Femeninas o de las Sonatas, Almagro hace con su libro inaugural profesión de fe modernista, tal y como manifiesta el propio Valle en su prólogo, pues «Si en la literatura de hoy existe algo nuevo que pueda recibir con justicia el nombre de modernismo, es, ciertamente, un vivo anhelo de personalidad, y por eso sin duda advertimos en los escritores jóvenes más empeño por expresar sensaciones que ideas» (Valle-Inclán 1986, 
pág. XIV). De todo ello son buen ejemplo los cuentos que ofrece Almagro San Martín en Sombras de vida, que Valle-Inclán define como «pequeños poemas, breves, alados, llenos de sentimientos» (Valle-Inclán 1986, pág. XXII), a la vez que destaca su sensibilidad decadente, tan distinta de la «sensibilidad de los jayanes» (Valle-Inclán 1986, pág. XXII).

En esas fechas, Melchor Almagro San Martín lleva ya varios años viviendo con su familia en la capital madrileña, adonde trasladaron su domicilio en 1898. Allí, el joven se encontraba por completo integrado en la vida intelectual y cultural, alternando su vida social mundana en ambientes aristocráticos y de la alta burguesía con sus contactos con los círculos literarios, y de manera especial con el naciente movimiento modernista, cuyas tertulias frecuenta, principalmente en el Café de Madrid, capitalizada en torno a Pío Baroja y el futuro Azorín, y en el Café de la Montaña, en torno a Jacinto Benavente y a Ramón del Valle-Inclán.

La ebullición de esa activa vida cultural, junto con la afinidad hacia el movimiento de renovación literaria del modernismo, que se puede considerar ya triunfante en ese momento, serán transmitidos como fecunda herencia a su primo carnal, aunque once años menor, el futuro crítico y escritor, además de académico de la RAE, Melchor Fernández Almagro. De este modo, Fernández Almagro lo relatará en su libro autobiográfico Viaje al siglo XX, aludiendo a los periodos vacacionales en que la familia de su primo regresaba a Granada, lo que les daba ocasión de compartir momentos de ocio que solían tener como punto de conexión los libros. Melchor Almagro, cuya familia poseía una bien nutrida biblioteca, le aconseja lecturas y le relata las novedades de la vida literaria madrileña:

Mi primo Melchor buscó para mí algunas novelas: Los reyes en el destierro, de Daudet en español, y me agradó mucho más aún Lettres de mon Moulin, muy especialmente el capítulo o cuento titulado «Les étoiles». Pero él llegaba siempre, de Madrid o de Granada, con libros nuevos, cuyos autores constituían para mí una revelación. Me interesó, más que ninguno, «Azorín», del que leí, de un tirón, Confesiones de un pequeño filósofo. Mi primo hablaba también de Unamuno, de Pío Baroja, de Rubén Darío, de un joven Juan R. Jiménez, nuevo Bécquer... A todos los conocía él personalmente, por alternar en las tertulias de este o aquel café o en aquel Ateneo... Al que más trataba era a Valle-Inclán, que había prologado su primer libro, Sombras de vida, lectura que fue para mí muy grata (Fernández Almagro 1962, págs. 198-199).

Conviene dar un pequeño salto atrás en el tiempo para recuperar una colaboración literaria de Almagro San Martín, que se encuentra cronológicamente situada entre las dos que publica en la revista La Alhambra, recién comentadas. En efecto, antes de ese momento de eclosión literaria inaugural que 
supondrá la publicación de Sombras de vida, y antes de su plena integración en los círculos literarios más renovadores, Melchor Almagro iniciará una fugaz colaboración con La Revista Moderna (Madrid). El único artículo que en ella publica lleva por título "Cosas de mi tierra», aparecido el 24 de marzo de 1899. Se trata de un relato en la órbita del romanticismo tardío, con influencia también del costumbrismo andalucista, y muy en la línea de las diversas leyendas y tradiciones que daría a conocer a lo largo de los años su prolífico paisano y compañero en la Cofradía del Avellano, Antonio Joaquín Afán de Ribera. Se puede señalar el dato ciertamente curioso de que, cuando Ángel Ganivet inmortalice a los miembros de la Cofradía en su novela Los trabajos del infatigable creador Pío Cid (1898), presentándolos bajo nombres en clave, sólo incluirá a dos con denominación idéntica: Gaudente el Viejo (Antonio Joaquín Afán de Ribera) y Gaudente el Joven (Melchor Almagro San Martín), quienes eran, respectivamente, el más veterano y el benjamín del grupo (Ganivet 1983, pág. 346).

En cuanto a la publicación, se puede decir que La Revista Moderna había sido fundada en marzo de 1897, logrando mantenerse hasta finales de octubre de 1899. Su director era Eduardo Sánchez de Castilla, mientras que la dirección artística la ejercía Félix de la Torre. Se presentaba con abundantes ilustraciones, constaba de dieciséis páginas y, como explica Pilar Celma en su documentado estudio sobre las revistas de fin de siglo, «El contenido estaba formado por cuentos, poesías, artículos humorísticos y crónicas» (Celma Valero 1991, pág. 116). Entre sus colaboradores pueden destacarse los nombres de Jacinto Octavio Picón, Joaquín Dicenta, Felipe Trigo, Ramón de Campoamor, Salvador Rueda y, con una participación única, Jacinto Benavente, Emilia Pardo Bazán, Clarín, o Ramón del Valle-Inclán.

Al igual que sucede con su relación con La Revista Moderna, una única colaboración de Almagro San Martín se encuentra igualmente en dos revistas, considerablemente diferentes, en las que participará en 1903 de manera prácticamente simultánea. Se trata, por un lado, de la rara y muy efímera revista $L a$ Crítica: crónica semanal, y por otro, de la que será, sin duda, gozosa portavoz del modernismo, Helios.

En cuanto a la primera, es poco lo que se conoce al respecto. Recogida en el muy útil catálogo de Publicaciones literarias españolas 1900-1950 que editará la Hemeroteca Municipal de Madrid en 1998, se tiene conocimiento de que se inició en Madrid el 9 de diciembre de 1903, manteniéndose tan sólo durante seis números, hasta el 13 de enero de 1904. Su director fue Joaquín López. En diciembre publicó Melchor Almagro su artículo titulado «Plumas industriales». 
En ese mismo mes precisamente verá la luz la reseña sobre La novela de la sangre, de Carlos Octavio Bunge, que Almagro publica en Helios. Como afirma Donald F. Fogelquist, «La historia más viva y más fiel que se pudiera encontrar de este periodo es la que está escrita en las páginas de una de su revistas literarias: Helios» (Fogelquist 1975, pág. 327).

Aunque es de sobra conocida por especialistas y estudiosos del modernismo, se puede presentar sucintamente con algunos de sus datos más significativos: tenía periodicidad mensual y estaba editada con gran cuidado, en papel de calidad y con ilustraciones -si bien no demasiado abundantes- de inspiración claramente modernista y filiación prerrafaelita, «presidida desde su portada por el dios Helios que conduce sus caballos en veloz carrera» (Celma Valero 1991, pág. 87). Al parecer, la idea de la revista, con un carácter esencialmente literario, surgió en 1902, durante una de las ocasiones en que los habituales vinculados con la nueva literatura visitaban a Juan Ramón Jiménez en el madrileño Sanatorio del Rosario. Su primer número apareció en abril de 1903 y se mantuvo hasta mayo de 1904, con un total de catorce números que, aunque suponen una vida efímera, arrojan un balance claramente positivo. Según el pormenorizado estudio que dedicó a esta publicación Patricia O'Riordan, Helios se caracterizaba por su espíritu militante y vital, por lo que «debe considerarse como la revista del modernismo ascendente, triunfante» (O’Riordan 1973, pág. 72). Vinculada con el propio Juan Ramón, así como con Gregorio Martínez Sierra, en sus páginas se encuentran las firmas de los hermanos Machado, Rubén Darío, Alejandro Sawa, Santiago Rusiñol, Julio Pellicer, José Ortiz de Pinedo, Pedro González Blanco, etcétera.

La única colaboración de Melchor Almagro consistirá, como ya se ha adelantado, en una reseña del libro del sociólogo, jurista y escritor argentino Carlos Octavio Bunge, La novela de la sangre, una obra que, sorprendentemente, a pesar de aparecer su reseña en el número de Helios correspondiente a diciembre de 1903, lleva en su pie de imprenta la fecha de 1904. Se trata de una novela histórica, que pretende denunciar la crueldad del gobierno de Juan Manuel de Rosas: «La nación argentina, dominada por el tirano Rosas, surge ante los asombrados ojos del lector, que ve desfilar, en pesadilla de sangre, tormentos, suplicios, martirios refinados y neuróticos» (Almagro San Martín 1903b, pág. 624).

Sin embargo, a pesar de los indudables méritos que se encuentran en la obra, Almagro lamenta que «el Sr. Bunge no cuide más su estilo», ya que, en su opinión, «Escribe al correr de la pluma, sin corregir ni limar» (Almagro San Martín 1903b, pág. 624). 
Pocos meses antes había sido Melchor Almagro el reseñado, pues, en efecto, en el número de julio de Helios Gregorio Martínez Sierra se va a ocupar de su recién aparecido Sombras de vida. Elogiando el conjunto de relatos y a su autor («Tiene Almagro preclaro abolengo intelectual; es culto y sabe de la vida. Tiene en su estilo plácido las sales de la ironía, supremas conservadoras de toda obra artística, y entiende el artificio engendrador del interés» (Martínez Sierra 1903, pág. 500), sin embargo, llamativamente, lo encuentra ajeno al modernismo, manifestándose en este particular en contra de la opinión expresada por Valle-Inclán en el prólogo, como él mismo admite. Para Martínez Sierra, Almagro no sería modernista, sino «innovador», puesto que «El estilo, libre de la tortura afiligranada que ahora se usa, tiene la mansa y clara placidez de las lenguas ancestrales» (Martínez Sierra 1903, pág. 500).

Durante los siguientes años, aunque Melchor Almagro colabora en algunos periódicos y de igual modo participa activamente en la vida literaria (por ejemplo, y como recogen diversos medios de prensa: en marzo de 1904 asistirá al banquete de homenaje a Benito Pérez Galdós en Fornos; hacia finales de ese mismo mes, al que se le ofrece a Emilia Pardo Bazán con motivo del éxito del estreno de su diálogo dramático La suerte; en febrero de 1905 firma el manifiesto conjunto contra el Nobel a José de Echegaray que se difundirá en la prensa; o, en noviembre de 1908, se suma a la carta, firmada por un gran número de escritores, en la que se solicita a Alejandro Pidal que retire su candidatura para la presidencia de la Academia en beneficio de Marcelino Menéndez Pelayo), no abundarán sus colaboraciones en publicaciones literarias.

Habrá que esperar hasta casi finales de 1910, en que su relato Primavera en la nieve (Escenas berlinesas) aparece incluido en el número 99 de la popular colección de literatura breve Los Contemporáneos (Madrid). Aunque no se trata en puridad de una revista, el carácter eminentemente literario de esta publicación periódica revela más que aconsejable la consideración de la colaboración de Melchor Almagro en el presente artículo. Como es bien sabido, dicha colección fue fundada en 1909 por Eduardo Zamacois, tras el litigio que lo obliga a abandonar su inicial y muy exitosa El Cuento Semanal (19071912). Frente a ésta, de la que sigue estilo, características y contenidos, su duración en el tiempo será mucho mayor, ya que logrará mantenerse hasta abril de 1926. Significativamente, y como bien explica el que con toda probabilidad haya sido el máximo especialista en el tema de las colecciones de literatura breve que ha habido en España, Alberto Sánchez Álvarez-Insúa, Zamacois no concibe El Cuento Semanal ni Los Contemporáneos como «una simple colección de novelas, sino como una auténtica revista de información cultural» (Sánchez Álvarez-Insúa 2007, pág. 95). De este modo, en las páginas segunda 
y tercera de portada se situaban noticias y declaraciones de intención, comunicaciones con los lectores e informaciones de tipo literario, que fundamentalmente (aunque no sólo) consistían en reseñas de libros y revistas.

No obstante, antes de comentar con mayor detalle la colaboración de noviembre de 1910 de Almagro San Martín en Los Contemporáneos, y aunque no posee un carácter estrictamente literario, dado el indudable interés que ofrece la revista sí que haremos siquiera una mención al artículo que Melchor Almagro publica el 31 de enero en la madrileña revista Faro, titulado «El caballero de la democracia». Dicha revista tiene especial relieve puesto que fue «la primera empresa editorial y cultural que el prestigioso filósofo José Ortega y Gasset puso en marcha a lo largo de su vida» (González Soriano 2009, pág. 155), como aclara José Miguel González Soriano en su estudio sobre la misma. Iniciada el último domingo de febrero de 1908, con carácter semanal, se escoge un nombre, Faro, «suficientemente explícito que pretendía simbolizar el inicio de una nueva forma de dar luz a la cultura española» (González Soriano 2009, pág. 162). Debemos entender, en este contexto, «cultura» en el sentido más amplio posible, por lo que en las páginas de esta publicación encontrarán cabida, «con igual fuerza, la literatura, las ciencias, la crítica literaria y musical, al pedagogía, etc., con la actualidad política y las materias económicas» (González Soriano 2009, pág. 171). De hecho, la única colaboración de Almagro presente en Faro versará sobre la política alemana.

Y curiosamente, ése -la realidad alemana- será el punto de conexión con la última de sus colaboraciones que repasaremos, es decir, la mencionada Primavera en la nieve (Escenas berlinesas), ambientada en Berlín y, con toda probabilidad, fruto de las experiencias del periodo que pasó completando sus estudios de Leyes, especializándose en Derecho Político, en la célebre Universidad de Heidelberg.

La narración retoma las descripciones de la vida mundana y frívola que se encuentran en otras obras de Almagro, para contraponerlas bruscamente con un final triste y desesperanzado. Una síntesis del argumento presenta a Loren, un joven español de familia acomodada que viaja a Berlín para estudiar. Allí conoce a Frida, una muchacha humilde y trabajadora, maltratada por su propia familia, y de la que Loren se enamora locamente. Al quedar embarazada, Loren decide compartir su vida con la ingenua joven, que ha sido expulsada del hogar por un padre intransigente y déspota. Pasan unos meses de felicidad ideal, cuando llega la noticia de que el padre del muchacho se encuentra enfermo. Obligado por esa circunstancia, Loren retorna a Madrid, no sin antes asegurar a Frida que volverá a por ella. Pero el joven acabará casándose en España con una rica heredera. Mientras, Frida llora su soledad desamparada y 
da a luz un niño muerto. El mensaje final del escritor, no exento de moraleja, es que el suceso que ha narrado se repite tristemente cada día, en un continuo ciclo de nuevas víctimas que reescriben una y otra vez la misma historia.

Unos meses antes de la publicación de esta obra, en mayo de 1910, Melchor Almagro San Martín había presentado una instancia ante el Ministro de Estado solicitando que se le realice el examen de aptitud necesario para poder concurrir a las oposiciones para el ingreso en el Cuerpo Diplomático (cf. Correa Ramón 2001, pág. 43). Tras realizar un brillante examen, Almagro aprueba la oposición con el número uno, lo que se le comunica oficialmente con fecha 1 de diciembre de 1910, enviándosele a su primer destino como Agregado diplomático en la Embajada de París, iniciándose así su carrera en el Cuerpo (cf. Correa Ramón 2001, págs. 45-64).

Desde sus sucesivos destinos en puestos diplomáticos, Melchor Almagro continuará escribiendo para periódicos y revistas, enviando artículos, crónicas, relatos, etc., y, de hecho, continuará haciéndolo -literalmente- hasta el momento de su muerte, acaecida el 12 de abril de 1947. Así, sus textos de este origen alcanzan los varios centenares, dispersos en hemerotecas, olvidados en colecciones, perdidos en publicaciones efímeras que, apenas vieron la luz, alcanzaron el extravío. Y es que se podría recordar un significativo pasaje de La voluntad (1902), donde José Martínez Ruiz explica:

Azorín ha pedido una colección vieja de un periódico. Una colección vieja es una colección del año 1890... Decía el maestro que nada hay más desolador que una colección de periódicos. Y es cierto. En ella parece como que quedan momificados los instantes fugitivos de una emoción, como que cristaliza este breve término de una alegría o de una amargura, jeste breve término que es toda la vida!... [...]

Azorín ha ido pasando hoja tras hoja y ha sentido una vaga sensación de desconsuelo. ¡Las crónicas que le parecieron brillantes hace diez años, son frívolas y ampulosas! ¡Los artículos que le parecieron demoledores son ridículamente candidos! Y después, iqué desfile tétrico de hombres que han vivido un minuto, de periodistas que han tenido una semana de gloria! Todos han hecho algo, todos han estrenado un drama, han pronunciado un discurso, han publicado veinte crónicas; todos gesticulan un momento ante este cinematógrafo, agitan los brazos, menean la pluma, mueven los músculos de la cara violentamente... luego se esfuman, desaparecen. Y cuando, después, al cabo de los años, los vemos en la calle, estos hombres ilustres se nos antojan fantasmas, aparecidos impertinentes, sombras que tienen el mal gusto de mostrarse ante las nuevas generaciones (Martínez Ruiz 1988, págs. 248-249). 


\section{Bibliografía}

Almagro San Martín, Melchor, «Cuentos. Del lodo», Nuestros días festivos (Granada), n. ${ }^{\circ}$ 1, 22 de marzo de 1896, pág. 23.

—, «El drama del calvario», Semanario infantil (Granada), n. ${ }^{\circ}$ 2, 29 de marzo de 1896, pág. 12.

—, «La mujer española», Semanario infantil (Granada), n. ${ }^{\circ}$ 3, 5 de abril de 1896, pág. 12.

-, «La mujer del torero», Semanario infantil (Granada), n. ${ }^{\circ}$ 4, 12 de abril de 1896, pág. 23.

—, «El hombre y la fiera», Semanario infantil (Granada), n. ${ }^{\circ}$ 5, 19 de abril de 1896, pág. 3.

—, «Voz del cielo», Semanario infantil (Granada), n. ${ }^{\circ}$ 6, 26 de abril de 1896, pág. 2.

- «La vuelta a la patria», Semanario infantil (Granada), n. ${ }^{\circ}$ 7, 3 de mayo de 1896, pág. 3.

—, « ¡Un chavico!», Semanario infantil (Granada), n. ${ }^{\circ}$ 8, 10 de mayo de 1896, pág. 13.

—, «La derrota», Semanario infantil (Granada), n. ${ }^{\circ}$ 9, 17 de mayo de 1896, pág. 12.

—, «La vuelta al hogar», Semanario infantil (Granada), n. ${ }^{\circ}$ 10, 24 de mayo de 1896, pág. 13.

—, «Un abandonado», Semanario infantil (Granada), n. ${ }^{\circ}$ 11, 31 de mayo de 1896, pág. 13.

—, «A mi padre», Semanario infantil (Granada), n. ${ }^{\circ}$ 12, 7 de junio de 1896, pág. 2.

—, «iLo que semos!», Semanario infantil (Granada), n. ${ }^{\circ}$ 14, 21 de junio de 1896, pág. 12.

—, «Patria o familia», Semanario infantil (Granada), n. ${ }^{\circ}$ 20, 2 de agosto de 1896, pág. 23.

—, «Patria o familia (Conclusión)», Semanario infantil (Granada), n. ${ }^{\circ}$ 21, 9 de agosto de 1896, pág. 12.

—, «Niñería. Al castizo escritor y querido amigo Matías Méndez Vellido», La Alhambra (Granada), t. I, 1898, n. ${ }^{\circ}$ 8, págs. 153-156.

—, «Cosas de mi tierra», La Revista Moderna (Madrid), n. ${ }^{\circ}$ 108, año III, 24 de marzo de 1899, s. p. [págs. 8-9].

-, «De Andalucía la triste. Fragmento de una carta», La Alhambra (Granada), t. VI, 1903, n. ${ }^{\circ} 134$, págs. 327-330.

- (1903a), «Plumas industriales», La Crítica (Madrid), diciembre de 1903.

- (1903b) «Los libros. La novela de la sangre, por Carlos Octavio Bunge», Helios (Madrid), t. II, n. ${ }^{\circ}$ 12, año I, diciembre de 1903, págs. 624-625. 
- (1903c), Sombras de vida, prólogo de Ramón María del Valle-Inclán, ed. facsímil, introd. Pere Gimferrer, Granada, Diputación de Granada, 1986.

—, «El caballero de la democracia», Faro (Madrid), n. ${ }^{\circ}$ 50, año II, 31 de enero de 1909, págs. 68-69.

-, Primavera en la nieve (Escenas berlinesas), Los Contemporáneos, Madrid, n. ${ }^{\circ}$ 99, 18 de noviembre de 1910.

—, Biografía del 1900, Madrid, Revista de Occidente, 1943 (2. ${ }^{2}$ ed., 1944); reed.: ed. y estudio introductorio Amelina Correa Ramón, Granada, Universidad de Granada, 2013.

-, «En torno al snobismo. Yo he dado un té», Domingo. Semanario nacional (Madrid), 23 de abril de 1944, pág. 1.

—, «Ángel Ganivet, el misterioso», Bajo los tres últimos Borbones. Retratos, cuadros, intimidades, Madrid, Afrodisio Aguado, 1945, págs. 178-179.

-, Teatro del mundo. Recuerdos de mi vida, ed., estudio introductorio y notas Amelina Correa Ramón, Granada, Diputación de Granada, 2001.

«Banquete en Fornos. Homenaje a Galdós», La Correspondencia de España (Madrid), 17 de marzo de 1904, pág. 2.

«Bibliografía», La Opinión (Granada), n. ${ }^{\circ}$ 61, 29 de marzo de 1896, pág. 3.

Bunge, Carlos Octavio, La novela de la sangre, Buenos Aires, La Nación, 1904.

CARRERE, Emilio, «La biografía de 1900», Madrid (Madrid), 23 de noviembre de 1943, pág. 3.

Celma VAlero, Pilar, Literatura y periodismo en las revistas del fin de siglo. Estudio e indices (1888-1907), Madrid, Júcar, 1991.

CORREA RAMÓN, Amelina, Melchor Almagro San Martín, noticia de una ausencia, Granada, Ficciones, 2001.

- Alejandro Sawa, luces de bohemia, Sevilla, Fundación José Manuel Lara, 2009.

Dorado Fernández, Carlos (dir.), Publicaciones literarias españolas, 1900-1950:

Catálogo, Madrid, Hemeroteca Municipal de Madrid, 1998, pág. 29.

Fernández Almagro, Melchor, Viaje al siglo XX, Madrid, Sdad. de Estudios y Publicaciones, 1962.

FogElQuist, Donald F., «Helios, voz de un renacimiento hispánico», en AA. VV., El Modernismo, ed. Lily Litvak, Madrid, Taurus, 1975, págs. 327-335.

GANIVET, Ángel [1896], Granada la bella, ed. Fernando García Lara, estudio prelim. y notas Ángel Isac, Granada, Diputación de Granada / Fundación Caja de Granada, 1996.

- [1898], Los trabajos del infatigable creador Pío Cid, ed. Laura Rivkin, Madrid, Cátedra, 1983.

GANIVET, Ángel et al, Libro de Granada 1899, Granada, Imp. Lit. Vda. e Hijos de P. V. Sabatel, 1899; ed. facsímil: Granada, Comares, 1987.

GIL BLAS, «Gran mundo. En honor de Emilia Pardo», La Correspondencia de España (Madrid), 27 de marzo de 1904, pág. 1. 
GONZÁlez Soriano, José Miguel, «Primer centenario de la revista Faro (19081909): origen, trayectoria y contenidos», Revista de Estudios Orteguianos (Madrid), n. ${ }^{\circ}$ 19, 2009, págs. 155-184.

LEON-BOYD [CASAL, Enrique], «De sociedad. En casa de D. Melchor Almagro San Martín. En honor de Benavente», La Correspondencia de España (Madrid), 21 de marzo de 1922, pág. 5.

«Los interiores artísticos. Cómo vive un escritor español», Elegancias (Madrid), n. ${ }^{\text {4 }}$, año I, abril de 1923.

MAnjón-CABEZA SÁnChez, Antonio, Guía de la prensa de Granada y provincia (1706-1989), Granada, ed. del autor, 1995, 2 vols.

MARTínez Ruiz, José [1902], La voluntad, 5. ª ed., Madrid, Castalia, 1988.

MARTínez Sierra, Gregorio, «Los libros. Melchor Almagro, Sombras de vida», Helios (Madrid), t. I, n. ${ }^{\circ}$ 4, año I, julio de 1903, pág. 500.

O'Riordan, Patricia, Helios, revista del modernismo (1903-1904), Madrid, Ábaco. Estudios sobre literatura española, 4, 1973, págs. 57-150.

Pardo López, M. ${ }^{a}$ Angustias; Guervós Madrid, M. ${ }^{a}$ del Carmen, La Alhambra. Granada (1884-85 y 1898-1924). Índices, Granada, Universidad de Granada, 1957.

SÁNCHEZ ÁlVAREZ-INSÚA, Alberto, «La colección literaria Los Contemporáneos. Una primera aproximación», Monteagudo (Murcia), 3. ${ }^{a}$ ép., n. ${ }^{\circ}$ 12, 2007, págs. 91-120.

«Semanario simpático», El Defensor de Granada (Granada), 23 de marzo de 1896, pág. 1.

«Una carta de Pidal. La presidencia de la Academia», La Correspondencia de España (Madrid), 22 de noviembre de 1908, pág. 1.

«Una obra del escultor Juan Cristóbal. Admirable busto del ilustre escritor y diplomático D. Melchor Almagro y San Martín», La Esfera (Madrid), 13 de mayo de 1922.

VALLE-InClán, Ramón del, «Prólogo», en Almagro San Martín, Melchor [1903], Sombras de vida, ed. facsímil, introd. Pere Gimferrer, Granada, Diputación de Granada, 1986, págs. IX-XIV.

VillaRTA, Ángeles, «Ángeles Villarta contra Melchor de Almagro San Martín», Domingo. Semanario nacional (Madrid), 30 de abril de 1944, pág. 3.

Viñes Millet, Cristina, Melchor Almagro, Granada, Comares, 1999.

Fecha de recepción: 09/04/2014

Fecha de aceptación: 04/09/2014 